\title{
Stark muss er/sie sein
}

\section{Liebe Leserinnen und Leser,}

Finanzvorstände haben es nicht einfach. Auf der einen Seite sind die Anforderungen an ihre technische und finanzielle Expertise in Zeiten der Krise höher denn je. Sie müssen die Liquidität und die Vermögenswerte des Unternehmens sichern, die Kostenstruktur schnell an neue Realitäten anpassen, den reibungslosen Betrieb einer effizienten Finanzorganisation auch im Lockdown sicherstellen und nicht zuletzt die finanzielle Kompetenz der Organisation in einer Vielzahl von Einzelfragen gewährleisten. Gleichzeitig sollen sie aber auch die überlebenswichtige digitale Transformation weiter vorantreiben, agile Denkmuster in der Finanzorganisation verankern und natürlich als strategischer Ratgeber eng mit dem CEO zusammenarbeiten. So wünschenswert dieses ambitionierte Bild aus betriebswirtschaftlicher Sicht ist, so schwierig ist die Umsetzung im Alltag.

Gerade in der Krise sind primär die traditionellen Kernkompetenzen eines Finanzvorstands gefragt. Dem Postulat eines breit aufgestellten CFOs, der gleichermaßen management-, datenund finanzorientiert ist, steht somit schnell das traditionelle Bild eines soliden Finanzers gegenüber, der die Zahlen im Griff hat und sich mit einer Rolle des Hüters der kaufmännischen Expertise zufriedengibt. Auch weil es hier in der Krise und auf dem Weg in die neue Realität nach Corona nun wahrlich mehr als genug zu tun gibt. Und nur allzu leicht geraten da weitergehende Ambitionen aus dem Blick. Auf Sicht gefährdet dieses enge Rollenbild aber die Stellung des Finanzvorstands. Wenn etwa transaktionale Finanzprozesse in funktionsübergreifenden Shared Service Centers weiter zentralisiert und im Zuge des viel beschworenen nächsten Digitalisierungsschubs automatisiert werden: Warum sollten diese an den CFO und nicht an einen COO, CIO oder den Vorstandsvorsitzenden berichten? Wenn Enterprise Analytics ebenfalls funktionsübergreifend organisiert werden und kundenbezogenen Fragen (zu Recht!) Priorität eingeräumt wird, warum sollten Data Labs zukünftig an den Finanzvorstand berichten? Die Liste ließe sich fortsetzen.

Es gilt daher, den aktuellen Bedeutungszuwachs im Weg aus der Krise nicht wieder abzugeben und den durch Digitalisierung und ein Umfeld hoher Unsicherheit getriebenen Wandel von Geschäftsmodellen nicht zuletzt als Chance für die Rolle des Finanzvorstands zu sehen. Dazu bedarf es aber starker CFOs, die sich nicht nur um die finanzielle Basis, sondern

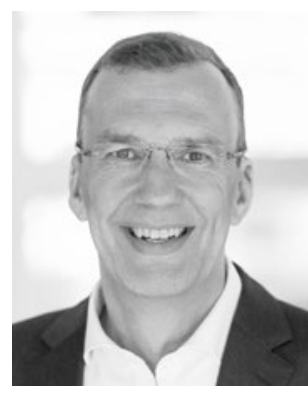

Utz Schäffer

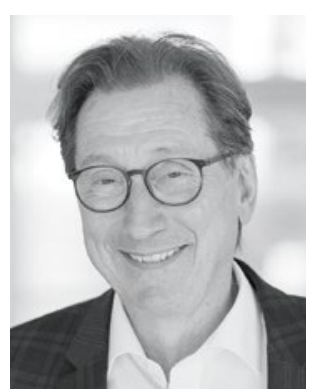

Jürgen Weber auch um ein profundes Verständnis des Geschäftsmodells und die Integration von finanziellen und nichtfinanziellen Kenngrößen bemühen. Die zudem dafür sorgen, dass der Finanzbereich lernt, die Analyse von Big Data für genauere Forecasts im Rahmen der Unternehmenssteuerung und für bessere Investitionsentscheidungen zu nutzen. Die ihre Teams davon begeistern, dass durchgängige Prozessketten in digitalen Geschäftsmodellen der umfassenden betriebswirtschaftlichen Bewertung bedürfen und dass kritisches Denken auf der Basis von Analyse und betriebswirtschaftlichem Know-how wichtiger ist denn je. Und die nicht zuletzt ihre Mannschaft und das Management des Unternehmens davon überzeugen, dass es neben technischen Lösungen darauf ankommt, die Kultur im Unternehmen zu verändern: hin zu (deutlich) mehr Transparenz und offenem Informationsaustausch, zu Unternehmertum und Verantwortung sowie nicht zuletzt zu einer gelebten Kraft des besseren Arguments.

Die Herausforderungen sind vielfältig, und vermutlich wird sich in den nächsten Jahren auch bei Finanzvorständen die Spreu sichtbarer vom Weizen trennen als bislang.

Viel Spaß bei der Lektüre wünschen Ihnen
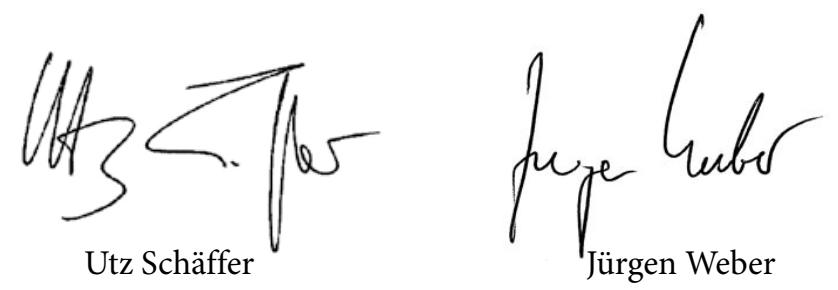